\title{
PENGARUH COUNTRY OF ORIGIN, BRAND AMBASSADOR, DAN KUALITAS PRODUK TERHADAP KEPUTUSAN PEMBELIAN GENERASI MILLENIAL PADA PRODUK NATURE REPUBLIC ALOE VERA 92\% SOOTHING GEL DI JAKARTA
}

\author{
Nursiti', Audia Fameira ${ }^{2}$ \\ Fakultas Ekonomi, Sekolah Tinggi Ilmu Ekonomi Y.A.I \\ Jl. Salemba Raya No 7-9, Jakarta Pusat \\ Email Korespondensi: nursiti.yai@gmail.com
}

\begin{abstract}
ABSTRAK
Penelitian ini bertujuan untuk mengetahui pengaruh Country of Origin, Brand Ambassador dan Kualitas Produk baik secara parsial maupun simultan terhadap Keputusan Pembeliaan. Penelitian ini menggunakan metode deskriptif dan kuantitatif. Populasi berjumlah 306 orang dan metode sampling yang digunakan adalah simple random sampling sehingga diperoleh sampel sebanyak 173 orang. Hasil dari penelitian ini membuktikan baik secara parsial maupun simultan Country of Origin, Brand Ambassador dan Kualitas Produk berpengaruh secara simultan dan signifikan terhadap Keputusan Pembelian dimana nilai koefisien korelasi sebesar 0,912 yang berarti Country of Origin, Brand Ambassador dan Kualitas Produk memiliki hubungan yang sangat kuat terhadap kepuasan konsumen. Dan dibuktikan dengan uji simultan dengan nilai sebesar $F_{\text {hitung }} 278,672>$ $\mathrm{F}_{\text {tabel }}$ 2,66 dan taraf signifikansi 0,000 $<0,05$ dengan demikian hipotesis penelitian $\mathrm{H} 4$ diterima, hal ini juga didukung dengan nilai $\mathrm{R}$ square sebesar 83,2\%. Hal ini menunjukkan besarnya kontribusi pengaruh Country of Origin, Brand Ambassador dan Kualitas Produk terhadap Keputusan Pembelian Generasi Millenial terhadap Nature Republik Aloe Vera 92\% Soothing Gel sebesar $83,2 \%$ sedangkan sisanya 16,8\% merupakan pengaruh faktor lain.
\end{abstract}

Kata Kunci : Country of Origin, Brand Ambassador, Kualitas Produk, Keputusan Pembelian

\begin{abstract}
This research aims to determine the influence of Country of Origin, Brand Ambassador and Product Quality both partially and simultaneously to the buying decision. This research uses descriptive and quantitative methods. The population amounted to 306 people and the sampling method used was simple random sampling so that the sample obtained as much as 173 people. The results of this research proved both partially and simultaneously the Country of Origin, Brand Ambassador and Product Quality is simultaneously and significantly influential to the Purchase Decision where the value of correlation coefficient is 0.912 means Country of Origin, Brand Ambassador and Product Quality has a strong relationship to customer satisfaction. And evidenced by simultaneous testing with a value of $F$ count $278.672>F$ table 2.66 and the equivalent significance of $0.000<0.05$ thus the $H 4$ research hypothesis was received, it is also supported with the $R$ square value of $83.2 \%$. This shows the magnitude of the contribution of Country of Origin, Brand Ambassador and Product Quality to the millennial Buying Decision on the Nature Republic Aloe Vera 92\% Soothing Gel by $83.2 \%$ while the remaining $16.8 \%$ is Influence other factors.
\end{abstract}

Keywords: Country of Origin, Brand Ambassador, Product Quality, Purchase Decision. 


\section{PENDAHULUAN}

Keputusan pembelian merupakan kegiatan individu yang secara langsung terlibat dalam pengambilan keputusan untuk melakukan pembelian terhadap produk yang ditawarkan oleh penjual. Keputusan pembelian dalam penelitian ini ditujukan untuk meneliti apakah generasi millenial akan menggunakan produk Nature Republic Aloe Vera 92\% Soothing Gel atau tidak.

Nature Republic secara resmi diluncurkan di Negeri Ginseng pada Maret 2009 yang ditandai dengan pembukaan toko pertamanya di Myeongdong. Nature Republic mengukuhkan diri sebagai brand kosmetik yang menggunakan bahan-bahan alami murni dari seluruh dunia untuk dinikmati oleh para pelanggan. Brand ini menggunakan berbagai bahan dasar alami yang ditemukan di berbagai belahan dunia, seperti Aloe Vera dari California, Shea Butter dari Afrika dan Argan dari Maroko. Terhitung sejak tahun 2013 hingga sekarang, Nature Republic menggaet boyband kenamaan Korea Selatan, EXO, sebagai brand ambassador-nya. Dengan alasan tersebut Nature Republic sangat memperhatikan Keputusan Pembelian dari generasi millennial.

Berdasarkan hasil survey dari beberapa pengguna Nature Republic, terdapat beberapa faktor yang dapat mempengaruhi keputusan pembelian produk Nature Republic Aloe Vera 92\% Soothing Gel yang membuat penulis tertarik untuk melakukan penelitian yang berjudul "Pengaruh Country Of Origin, Brand Ambassador, Dan Kualitas Produk Terhadap Keputusan Pembelian Generasi Millenial Pada Produk Nature Republic Aloe Vera Soothing Gel Di Jakarta"

\section{Keputusan Pembelian}

Kotler \& Armstrong (2013:129) mendefinisikan keputusan pembelian sebagai sebuah proses dimana konsumen mengenal masalahnya, mencari informasi mengenai produk atau merek tertentu dan mengevaluasi seberapa baik masing-masing alternatif tersebut dapat memecahkan masalahnya yang kemudian mengarah kepada keputusan pembelian. Dalam keputusan pembelian, ada beberapa peranan yang dapat dilakukan seseorang, yaitu:

\section{Pencarian Informasi}

Seseorang yang mulai timbul minatnya akan terdorong untuk mencari informasi lebih banyak.

2. Keputusan Membeli

Konsumen membentuk tujuan pembelian berdasarkan faktor-faktor seperti: pendapatan keluarga yang diharapkan, harga yang diharapkan, dan manfaat produk yang diharapkan.

3. Perilaku Pasca Pembelian

Setelah pembelian, konsumen mungkin mengalami konflik dikarenakan melihat fitur mengkhawatirkan tertentu atau mendengar hal-hal menyenangkan tentang merek lain dan waspada terhadap informasi yang mendukung keputusannya.

\section{Country of Origin}

Country of Origin (Listiana, 2013) adalah persepsi negara asal didefinisikan sebagai penilaian konsumen secara umum terhadap negara asal merek produk, berdasarkan informasi yang diterima dari berbagai sumber, yang terbentuk dari 3 dimensi meliputi 
keyakinan terhadap negara, keyakinan terhadap orang-orang di negara tersebut dan keinginan interaksi dengan negara tersebut.

\section{Brand Ambassador}

Menurut Lea-Greenwood (2012) Brand Ambassador adalah alat yang digunakan oleh perusahaan untuk komunikasi dan berhubungan dengan publik, dengan harapan mereka dapat meningkatkan penjualan. Hal tersebut juga termasuk dalam upaya yang dilakukan oleh perusahaan untuk mempengaruhi atau mengajak konsumen dengan menggunakan selebriti sebagai ikon untuk mempresentasikan citra terbaik dari suatu produk, agar konsumen tertarik untuk menggunakan produk tersebut. Karakteristik tersebut ialah:

1. Visibility (Kepopuleran)

Ialah popularitas yang melekat pada ambassador yang mewakili produk tersebut.

2. Credibility (Kredibilitas)

Adalah keahlian dan kepercayaan yang diberikan sang ambassador.

3. Attraction (Daya Tarik)

Yaitu meliputi daya tarik fisik, serta sekumpulan nilai seperti kemampuan intelektual, karakter gaya hidup yang dapat diterima khalayak dari seorang ambassador.

4. Power (Kekuatan)

Adalah tingkat kekuatan selebriti tersebut untuk membujuk para konsumen dalam membeli produk yang diiklankan.

\section{Kualitas Produk}

Kualitas produk merupakan kemampuan suatu produk dalam memenuhi keinginan konsumen. Kotler dan Armstrong (2015:253) mendefinisikan kualitas produk sebagai berikut, "Product quality is the characteristics of a product or service that bear on its ability to satisfy stated or implied customer needs". Kualitas produk memiliki indikatorindikator yaitu sebagai berikut:

1. Perfomance (Kinerja)

Merupakan karakteristik operasi dan produk inti (core product) yang dibeli.

2. Realibility (Keandalan)

Ukuran kemungkinan produk tidak akan mengalami kerusakan atau kegagalan dalam periode waktu tertentu.

3. Durability (Ketahanan)

Merupakan ukuran umur operasi harapan produk dalam kondisi biasa atau penuh tekanan, merupakan atribut berharga untuk produk-produk tertentu.

4. Form (Bentuk)

Bentuk sebuah produk dapat meliputi ukuran, bentuk, atau struktur fisik produk.

\section{METODE PENELITIAN}

Penelitian ini bersifat kualitatif yang dikuantitatifkan, data diperoleh langsung dari responden. Populasi dalam penelitian ini adalah generasi millennial yang menggunakan Nature Republic Aloe Vera 92\% Soothing Gel. Dalam penelitian ini digunakan beberapa Teknik analisis seperti: 
1. Uji Statistik Deskriptif Data Penelitian

2. Uji Instrumen Data

3. Uji Asumsi Klasik

4. Pengujian Hipotesis

\section{HASIL DAN PEMBAHASAN}

1. Uji Statistik Deskriptif

Tabel 1. Deskriptif Statistik Dimensi Country of Origin Statistics

VAR_COO
\begin{tabular}{|lr|r|}
\hline N & Valid & 173 \\
& Missing & 0 \\
Mean & & 29.2486 \\
Median & & 29.0000 \\
Mode & 30.00 \\
Std. Deviation & 3.20275 \\
Variance & 10.258 \\
Range & 18.00 \\
Minimum & 17.00 \\
Maximum & 35.00 \\
\hline
\end{tabular}

Tabel 2. Deskriptif Statistik Dimensi Brand Ambassador Statistics

VAR_BA
\begin{tabular}{|lr|r|}
\hline $\mathrm{N}$ & Valid & 173 \\
& Missing & 0 \\
Mean & & 33.7803 \\
Median & 34.0000 \\
Mode & 35.00 \\
Std. Deviation & 3.50386 \\
Variance & 12.277 \\
Range & 22.00 \\
Minimum & 18.00 \\
Maximum & 40.00 \\
\hline
\end{tabular}


Tabel 3. Deskriptif Statistik Dimensi Kualitas Produk Statistics

\begin{tabular}{|c|c|c|}
\hline \multirow[t]{2}{*}{$\bar{N}$} & & 173 \\
\hline & Missing & 0 \\
\hline \multicolumn{2}{|c|}{ Mean } & 45.8150 \\
\hline \multicolumn{2}{|c|}{ Median } & 46.0000 \\
\hline \multicolumn{2}{|c|}{ Mode } & 46.00 \\
\hline \multicolumn{2}{|c|}{ Std. Deviation } & 4.17501 \\
\hline \multicolumn{2}{|c|}{ Variance } & 17.431 \\
\hline \multicolumn{2}{|c|}{ Range } & 22.00 \\
\hline \multicolumn{2}{|c|}{ Minimum } & 33.00 \\
\hline \multicolumn{2}{|c|}{ Maximum } & 55.00 \\
\hline
\end{tabular}

Tabel 4

Deskriptif Statistik Keputusan Pembelian

Statistics

\begin{tabular}{|lr|r|}
\hline $\mathrm{N}$ & Valid & 173 \\
& Missing & 0 \\
Mean & & 41.0347 \\
Median & & 41.0000 \\
Mode & & 42.00 \\
Std. Deviation & & 4.13844 \\
Variance & & 17.127 \\
Range & & 22.00 \\
Minimum & 27.00 \\
Maximum & & 50.00 \\
\hline
\end{tabular}

Dari tabel Deksriptif di atas dapat diketahui bahwa rata-rata total dari Variabel Country of Origin adalah 29,24, Variabel Brand Ambassador sebesar 33,78, Variabel Kualitas Produk sebesar 45,81, dan Variabel Keputusan Pembelian memeiliki nilai rata-rata 41,03 yang berarti semua variabel berada pada tingkatan yang sebaran yang tinggi dan tidak terdapat masalah pada variabel interval kelasnya.

\section{Uji Instrumen Data}

\section{Uji Reabilitas}

Uji reliabilitas dapat dilakukan dengan menggunakan uji cronbach's alpha $(\alpha)$ dengan ketentuan jika $\alpha>0,60$ maka dikatakan reliabel. Sebaliknya apabila $\alpha<$ 0,60 maka dikatakan tidak reliable. 
Tabel 5

Uji Reliabilitas Variabel

\begin{tabular}{|c|c|c|c|}
\hline Variabel & $\begin{array}{c}\text { cronbach's } \\
\text { alpha } \\
\text { Hitung }\end{array}$ & $\begin{array}{c}\text { cronbach's } \\
\text { alpha tabel }\end{array}$ & Keterangan \\
\hline $\mathrm{X} 1$ & 0.766 & 0.6 & Reliabel \\
\hline $\mathrm{X} 2$ & 0.780 & 0.6 & Reliabel \\
\hline $\mathrm{X} 3$ & 0.796 & 0.6 & Reliabel \\
\hline $\mathrm{Y}$ & 0.733 & 0.6 & Reliabel \\
\hline
\end{tabular}

Dari hasil uji reliabilitas diperoleh nilai koefisien reabilitas angket X1 sebesar 0,766 X2 sebesar 0,780, X3 sebesar 0,796, dan Y sebesar 0,733. Berdasarkan hasil nilai koesfisien realibilitas dapat disimpulkan bahwa semua angket dalam penelitian ini reliabel atau konsisten sehingga dapat digunakan sebagai instrument penelitian.

\section{Uji Asumsi Klasik}

Uji Normalitas

\section{Tabel 6}

Uji Normalitas Data Dimensi Keputusan Pembelian (Y)

One-Sample Kolmogorov-Smirnov Test

\begin{tabular}{|ll|l|}
\hline & & VAR_KEP_PEM \\
\hline $\mathrm{N}$ & & 173 \\
Normal & Mean & 41.0347 \\
Parameters ${ }^{\mathrm{a}, \mathrm{b}}$ & Std. & 4.13844 \\
& Deviation & \\
Most Extreme & Absolute & .087 \\
Differences & Positive & .063 \\
& $\quad$ Negative & -.087 \\
& Kolmogorov-Smirnov Z & 1.147 \\
Asymp. Sig. (2-tailed) & .144 \\
\hline
\end{tabular}

a. Test distribution is Normal.

b. Calculated from data.

Berdasarkan Uji Normalitas diatas dapat diketahui nilai signifikansi sebesar 0,144 $>0,050$ sehingga dapat disimpulkan bahwa nilai residual berdistribusi normal. 


\section{Uji Multikolinieritas}

Tabel 7

Uji Multikolinieritas

\begin{tabular}{|c|c|c|}
\hline \multirow[b]{2}{*}{ Model } & \multicolumn{2}{|c|}{ Collinearity Statistics } \\
\hline & Tolerance & VIF \\
\hline $1 \quad$ (Constant) & & \\
\hline VAR_COO & .518 & 1.931 \\
\hline VAR_BA & .328 & 3.048 \\
\hline VAR_KP & .345 & 2.894 \\
\hline
\end{tabular}

Berdasarkan tabel 7 dapat diketahui patokan nilai VIF $<10,00$ dan Tolerance $>$ 0,10 yaitu pada variabel Country of Origin (VAR_COO) yaitu 1,931 dan Tolerance sebesar 0,518. Pada Variabel Brand Ambassador (VAR_BA) nilai VIF sebesar 3,048 dan Tolerance 0,328. Kemudian pada Variabel Kualitas Produk (VAR_KP) nilai VIF sebesar 2,894 dan Tolerance sebesar 0,345. Sehingga tidak terjadi Multikolinearitas maka data ini layak dilakukan pengujian Regresi Linear berganda.

Uji Heterokedastisitas

\section{Gambar 1}

Uji Asumsi Klasik Heteroskedastisitas Terhadap Y

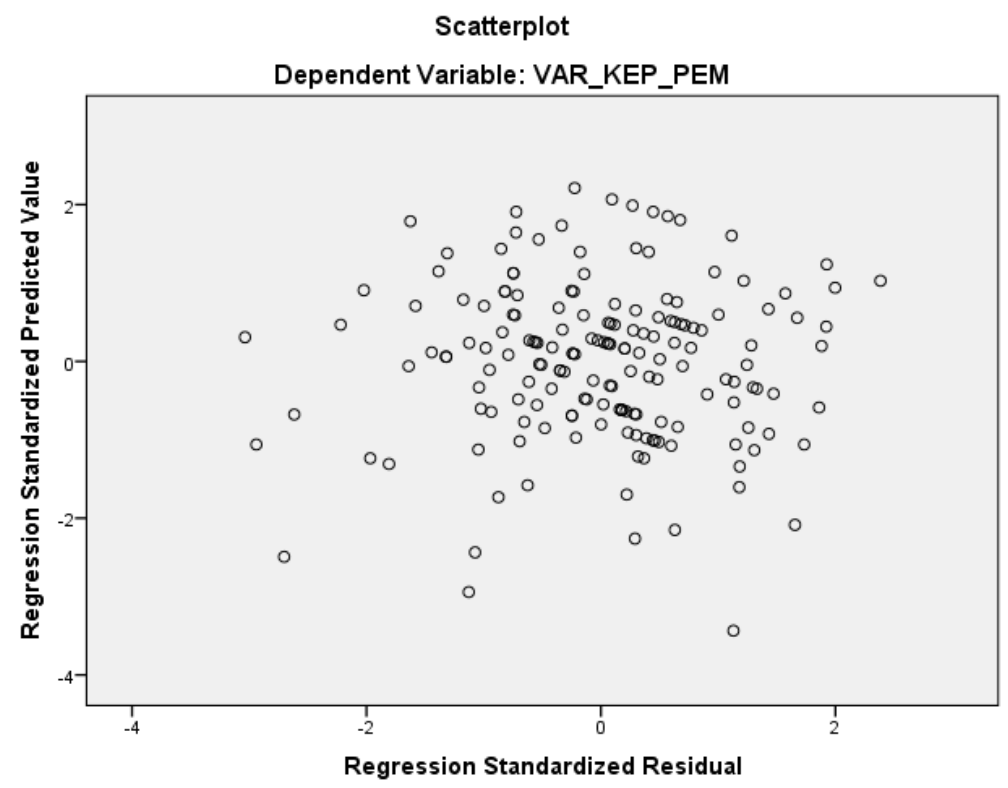

Dari titik-titik di atas dapat diketahui bahwa titik-titik menyebar dengan pola tidak jelas di atas dan di bawah angka 0 pada sumbu Y maka dapat di simpulkan bahwa model regresi asumsi tidak terjadi heteroskedastisitas. 


\section{Pengujian Hipotesis Uji Simultan (Uji F)}

Tabel 8

Korelasi Berganda X1 X2 dan X3 - Y

\begin{tabular}{|c|c|c|c|c|c|}
\hline \multicolumn{6}{|c|}{ ANOVA $^{\mathbf{a}}$} \\
\hline Model & $\begin{array}{l}\text { Sum of } \\
\text { Squares }\end{array}$ & $\mathrm{df}$ & $\begin{array}{c}\text { Mean } \\
\text { Square }\end{array}$ & $\mathrm{F}$ & Sig. \\
\hline 1 Regression & 2450.438 & 3 & 816.813 & 278.672 & $.000^{\mathrm{b}}$ \\
\hline Residual & 495.354 & 169 & 2.931 & & \\
\hline Total & 2945.792 & 172 & & & \\
\hline
\end{tabular}

Keterangan :

- Jika nilai sig <0,05 atau $\mathrm{F}$ hitung $>\mathrm{F}$ tabel maka terdapat pengaruh variabel $\mathrm{X}$ secara simultan terhadap variabel $\mathrm{Y}$

- Jika nilai sig > 0,05 atau $\mathrm{F}$ hitung $<\mathrm{F}$ tabel maka tidak terdapat pengaruh variabel $\mathrm{X}$ secara simultan terhadap variabel $\mathrm{Y}$

$\mathrm{F}$ tabel $=\mathrm{F}(\mathrm{k} ; \mathrm{n}-\mathrm{k})=\mathrm{F}(3 ; 173)=2,66$

Berdasarkan perhitungan di atas didapat nilai Fhitung sebesar 278,672 nilai ini selanjutnya dibandingkan dengan nilai dari Ftabel sebesar 2,66. Dari perbandingan tersebut dapat dilihat bahwa nilai dari Fhitung sebesar 278,672 lebih besar dari nilai Ftabel sebesar 2,66, maka dapat diambil kesimpulan bahwa HO ditolak, jadi antara Dimensi Country of Origin, Dimensi Brand Ambassador, dan Dimensi Kualitas Produk secara bersama terhadap Keputusan Pembelian memiliki signifikansi hubungan.

Tabel 9

\section{Regresi Berganda X1 X2 dan X3 - Y}

\begin{tabular}{|c|c|c|c|c|c|}
\hline \multicolumn{6}{|c|}{ Coefficients $^{\mathbf{a}}$} \\
\hline \multirow[b]{2}{*}{ Model } & \multicolumn{2}{|c|}{$\begin{array}{c}\text { Unstandardized } \\
\text { Coefficients } \\
\end{array}$} & \multirow{2}{*}{$\begin{array}{c}\begin{array}{c}\text { Standardized } \\
\text { Coefficients }\end{array} \\
\text { Beta }\end{array}$} & \multirow[b]{2}{*}{$\mathrm{t}$} & \multirow[b]{2}{*}{ Sig. } \\
\hline & $\mathrm{B}$ & Std. Error & & & \\
\hline $1 \quad$ (Constant) & -1.501 & 1.483 & & -1.012 & .313 \\
\hline VAR_COO & .241 & .057 & .187 & 4.257 & .000 \\
\hline VAR_BA & .273 & .065 & .231 & 4.189 & .000 \\
\hline VAR_KP & .574 & .053 & .579 & 10.782 & .000 \\
\hline
\end{tabular}

a. Dependent Variable: VAR_KEP_PEM 
Dapat disimpulkan bahwa persamaan regresi linier berganda sebagai berikut:

$\mathrm{Y}=-1,501+0,241 \mathrm{X} 1+0,273 \mathrm{X} 2+0,574 \mathrm{X} 3+€$

Uji Parsial (t)

Tabel 10

Korelasi Sederhana X1 - Y

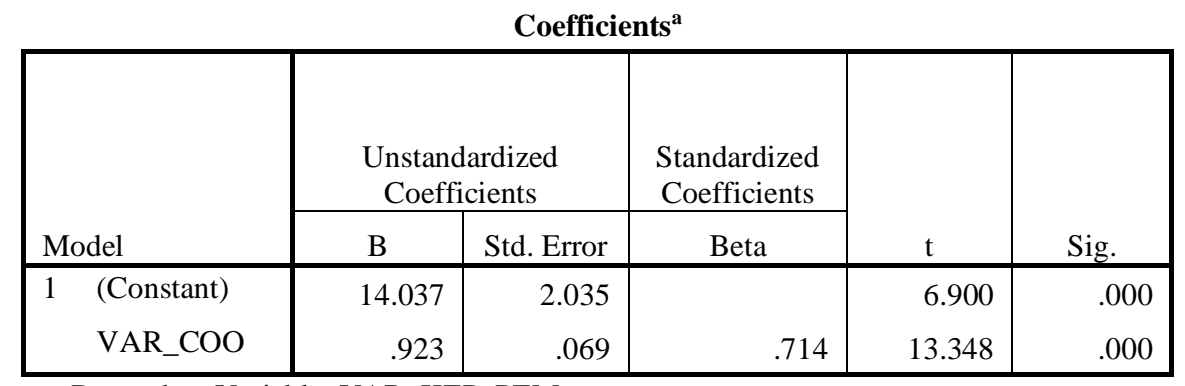

a. Dependent Variable: VAR_KEP_PEM

Variabel Country of Origin mempunyai nilai sig $0,000<0,050$ dan mempunyai t hitung 13,348 > dari t tabel 1,653 maka dapat disimpulkan secara parsial bahwa Country of Origin berpengaruh signifikan terhadap Keputusan Pembelian, Ha diterima.

Tabel 11

\section{Korelasi Sederhana X2 - Y}

\begin{tabular}{|c|c|c|c|c|c|}
\hline & & Coeffici & & & \\
\hline \multirow[b]{2}{*}{ Model } & \multicolumn{2}{|c|}{$\begin{array}{l}\text { Unstandardized } \\
\text { Coefficients }\end{array}$} & \multirow{2}{*}{$\begin{array}{c}\text { Standardized } \\
\text { Coefficients }\end{array}$} & \multirow[b]{2}{*}{$\mathrm{t}$} & \multirow[b]{2}{*}{ Sig. } \\
\hline & B & Std. Error & & & \\
\hline $1 \quad$ (Constant) & 8.523 & 1.778 & & 4.794 & .000 \\
\hline VAR_BA & .962 & .052 & .815 & 18.382 & .000 \\
\hline
\end{tabular}

a. Dependent Variable: VAR_KEP_PEM

Variabel Brand Ambassador mempunyai nilai sig 0,000 < 0,050 dan mempunyai t hitung 18,382 > dari t tabel 1,653 maka dapat disimpulkan secara parsial bahwa Brand Ambassador berpengaruh signifikan terhadap Keputusan Pembelian, Ha diterima.

Tabel 12

\section{Korelasi Sederhana X3 - Y}

\begin{tabular}{|c|c|c|c|c|c|}
\hline \multicolumn{6}{|c|}{ Coefficients $^{\mathrm{a}}$} \\
\hline \multirow[b]{2}{*}{ Model } & \multicolumn{2}{|c|}{$\begin{array}{l}\text { Unstandardized } \\
\text { Coefficients }\end{array}$} & \multirow{2}{*}{$\begin{array}{c}\text { Standardized } \\
\text { Coefficients } \\
\text { Beta }\end{array}$} & \multirow[b]{2}{*}{$\mathrm{t}$} & \multirow[b]{2}{*}{ Sig. } \\
\hline & $\mathrm{B}$ & Std. Error & & & \\
\hline $1 \quad$ (Constant) & .965 & 1.641 & & .588 & .557 \\
\hline VAR_KP & .875 & .036 & .882 & 24.515 & .000 \\
\hline
\end{tabular}


a. Dependent Variable: VAR_KEP_PEM

Variabel Kualitas Produk mempunyai nilai sig 0,002 < 0,050 dan nilai t hitung 24,515 < 1,653 maka dapat disimpulkan bahwa Kualitas Produk berpengaruh signifikan terhadap Keputusan Pembelian, Ha diterima.

Uji Koefisien Determinasi $\left(\mathbf{R}_{2}\right)$

\section{Tabel 13}

Koefisien Determinasi X1 X2 dan X3 - Y

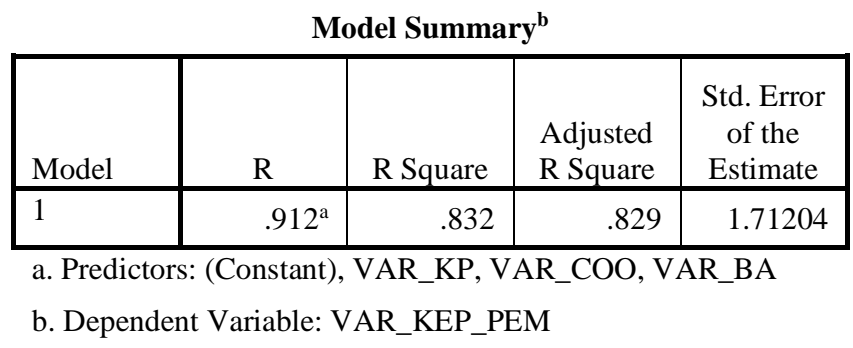

$\mathrm{KD}=0,9122 \times 100 \%=83,2 \%$

Koefisien determinasi sebesar 83,2\% artinya bahwa kontribusi Dimensi Country of Origin, Dimensi Brand Ambassador, dan Dimensi Kualitas Produk secara bersama terhadap Keputusan Pembelian sebesar 83,2\%. Sedangkan sisanya sebesar 16,8\% merupakan kontribusi dari faktor-faktor lain yang tidak diteliti.

\section{KESIMPULAN}

Berdasarkan uraian dan analisis yang telah dikemukan pada bab-bab sebelumnya, maka hasil penelitian ini dapat disimpulkan sebagai berikut:

1. Hasil penelitian hipotesis pertama

Variabel Dimensi Country of Origin (X1) terbukti berpengaruh positif dan signifikan terhadap Keputusan Pembelian (Y) dengan nilai koefisien regresi 0,923 dan nilai thitung 13,348 > t tabel 1,653 dan taraf signifikan sig. $0,00 \leq 0,05$. dan kontribusi variable Dimensi Country of Origin (X1) terhadap variabel Keputusan Pembelian (Y) sebesar $51,0 \%$ dan besarnya faktor lain yang mempengaruhi variabel Keputusan Pembelian (Y) di luar penelitian ini adalah sebesar 49,0\%.

2. Hasil penelitian hipotesis kedua

Variabel Dimensi Brand Ambassador (X2) terbukti berpengaruh positif dan signifikan terhadap Keputusan Pembelian (Y) dengan nilai koefisien regresi 0,962 dan nilai thitung 18,382 > t tabel 1,653 dan taraf signifikan sig. $0,00 \leq 0,05$. dan kontribusi variable Dimensi Brand Ambassador (X2) terhadap variabel Keputusan Pembelian (Y) sebesar $66,4 \%$ dan besarnya faktor lain yang mempengaruhi variabel Keputusan Pembelian (Y) di luar penelitian ini adalah sebesar 33,6\%.

3. Hasil penelitian hipotesis ketiga

Variabel Dimensi Kualitas Produk (X3) terbukti berpengaruh positif dan signifikan terhadap Keputusan Pembelian (Y) dengan nilai koefisien regresi 0,875 dan nilai 
thitung 24,515 > t tabel 1,653 dan taraf signifikan sig. $0,00 \leq 0,05$. dan kontribusi variable Dimensi Kualitas Produk (X3) terhadap variabel Keputusan Pembelian (Y) sebesar $77,8 \%$ dan besarnya faktor lain yang mempengaruhi variabel Keputusan Pembelian (Y) di luar penelitian ini adalah sebesar 22,2\%.

4. Hasil penelitian hipotesis keempat

Variabel Dimensi Country of Origin (X1) Dimensi Brand Ambassador (X2) dan Dimensi Kualitas Produk (X3) secara bersama-sama/simultan terbukti berpengaruh positif dan signifikan terhadap Keputusan Pembelian (Y) dengan nilai Fhitung 278,672 $>$ Ftabel 2,66 dan taraf signifikan sig. $0,00 \leq 0,05$. dan kontribusi variable Dimensi Country of Origin (X1) Dimensi Brand Ambassador (X2) Dimensi Kualitas Produk (X3) secara simultan terhadap variabel Keputusan Pembelian (Y) sebesar 83,2\% dan besarnya faktor lain yang mempengaruhi variabel Keputusan Pembelian (Y) di luar penelitian ini adalah sebesar $16,8 \%$.

\section{DAFTAR PUSTAKA}

Ahmed, Z. U., Johnson, J. P., Yang, X., Fatt, C. K., Teng, H. S., \& Boon, L. C. (2004). Does country of origin matter for low-involvement products?. International marketing review.

Ferdinand, A. (2011). Metode Penlitian Manajemen Pedoman Penelitian Untuk Menulis Skripsi Tesis dan Disertai Ilmu Manajemen, Edisi Ke Tiga.

Doucett, E. (2008). Creating your library brand: communicating your relevance and value to your patrons. American Library Association. Chicago : American Library Association (E-books).

Echdar, S. (2017). Metode Penelitian Manajemen dan Bisnis. Bogor: Ghalia Indonesia.

Listiana, E. (2012). Pengaruh country of origin terhadap perceived quality dengan moderasi etnosentris konsumen. Jurnal Administrasi Bisnis, 8(1).

Erna Listiana., (2014), Pengaruh Country of Origin of Brand dan Country of Manufacture Terhadap Asosiasi Merek (Studi Pada Pelanggan Produk Elektronik)

Tjiptono, F., \& Chandra, G. (2016). Service, Quality dan Satisfaction Edisi 4. Yogyakarta: Andi Offset.

Royan, F. M. (2004). Marketing selebrities. Elex Media Komputindo.

Ghozali, I. (2006). Aplikasi analisis multivariate dengan program SPSS. Badan Penerbit Universitas Diponegoro.

Jaffe, E. D., \& Nebenzahl, I. D. (2001). National Image ND Competitive Advantage: The Theory and Practice of Country-of-origin Effect. Copenhagen business school press. 
Keegan, L. (2007). Sikap Konsumen terhadap produk dari Negara asal yang berbeda (Untuk produk Handphhone).

Kotler, P., \& Keller, K. (2011). Marketing management 14th edition. Prentice Hall.

Kotler, P., \& Keller, K. (2012). Marketing management 14th edition. Prentice Hall.

Kotler, P., \& Keller, K. (2016). Marketing management 15th edition. Prentice Hall.

Ronny, K. (2007). Metode Penelitian Untuk Penulisan Skripsi dan Tesis Edisi Revisi. Jakarta: Penerbit PPM.

Gaynor, L. G. (2012). Fashion Marketing Communications E-book.

Lin, L. Y., \& Chen, C. S. (2006). The influence of the country-of-origin image, product knowledge and product involvement on consumer purchase decisions: an empirical study of insurance and catering services in Taiwan. Journal of consumer Marketing.

Pappu, R., Quester, P. G., \& Cooksey, R. W. (2006). Consumer-based brand equity and country-of-origin relationships. European Journal of marketing.

Permana, M. S., \& Haryanto, J. O. (2014). Pengaruh Country of origin, Brand Image Dan Persepsi Kualitas Terhadap Intensi Pembelian. Jurnal Manajemen Untar, 18(3), 112392.

Riduwan, K. (2012). Metode \& Teknik Menyusun Proposal Penelitian. Bandung: Mandar Maju.

Setiadi, N. (2013). Konsep dan praktek penulisan riset keperawatan edisi 2.

Sugiarto. (2016). Metodologi Penelitian Bisnis. Jakarta. Penebit Andi

Sugiyono (2009). Metodologi Penelitian Bisnis. Bandung: Alfabeta.

Sugiyono. (2005). Memahami Penelitian Kualitatif. Bandung: CV. Alfabeta.

Sugiyono. (2008). Metode Penelitian Kuantitatif Kualitatif dan R\&D. Bandung : Alfabeta

Sujarweni, V. W. (2014). Metode Penelitian: Lengkap, praktis, dan mudah dipahami.

Rosyidi, S. (2018). Analisis Pengaruh Brand, Country of Design dan Country of Assembly Pada Persepsi Kualitas dan Niat Beli. potensio, 11(01).

Tranggono, R. I., \& Latifah, F. (2007). Buku pegangan ilmu pengetahuan kosmetik. Jakarta: PT. Gramedia Pustaka Utama, 3(47), 58-59.

Mulyana, S., \& Wirakusumah, T. K. (2012). Hubungan Karakteristik Brand Ambassador Honda Spacy Helm-In dengan Tahapan Keputusan Pembelian Konsumen. Students e-Journal, 1(1), 27. 